\title{
Catalytic hydroconversion of pyrolytic bio-oil: understanding and limiting macromolecules formation
}

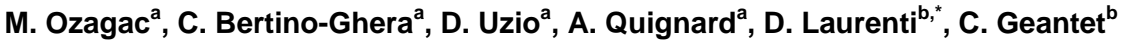 \\ aIFP Energies Nouvelles, Rond-point de l'échangeur de Solaize, BP3, 69360 Solaize, France \\ ${ }^{\mathrm{b}}$ IRCELYON, UMR5256 CNRS-UCBL, 2 avenue A. Einstein, 69626 Villeurbanne cedex, France \\ ${ }^{*}$ Corresponding author: dorothee.laurenti@ircelyon.univ-lyon1.fr
}

\begin{abstract}
Fast pyrolysis followed by catalytic hydroconversion is a value chain aimed to transform lignocellulosic biomass into biofuel or chemicals. During hydroconversion, desired catalytic deoxygenation reactions are in competition with thermal side reactions like condensation or oligomerization. These undesired pathways lead to high molecular weight compounds (i.e. macromolecules) that are responsible for catalyst deactivation and severe plugging of the reactor. We investigate here the impact of a phenolic compound on the formation of these macromolecules. Catalytic hydroconversion of a fast pyrolysis bio-oil and a bio-oil/guaiacol (50/50 wt\%) mixture were carried out in a batch reactor using a NiMo/alumina catalyst. An extended analytical strategy has been developed involving size-exclusion chromatography (SEC) and liquid state ${ }^{13} \mathrm{C}$ NMR dedicated to the in depth characterization of effluents as well as physicochemical analysis of the fresh and used catalyst (XRD, $\mathrm{Hg}$ porosimetry, $\mathrm{N}_{2}$ physisorption, STEM). This strategy allowed bringing new insights on aromatic structures larger than 1,000 g.mol ${ }^{-1}$ and their formation mechanism. This formation can be chemically inhibited by the introduction of organic component such as guaiacol. This stabilization was mainly observed and explained at low temperature and short reaction time.
\end{abstract}

Keywords: Biofuel $•$ Oligomers $\cdot$ Humins $\cdot$ SEC $\cdot$ Guaiacol $\cdot$ Hydrodeoxygenation

\section{Introduction}

Fast pyrolysis is a thermochemical liquefaction process that can be used to transform solid biomass into liquids [1, 2]. However, the obtained bio-oils (BO) have limited application due to their lower heating value compared to fossil fuels (respectively 16-17 against 42-44 MJ/kg), their acidity (Total Acid Number between 70 and $120 \mathrm{mg} \mathrm{KOH} \cdot \mathrm{g}^{-1}$ ), their immiscibility with hydrocarbons and their thermal instability resulting from high oxygen content [3]. Oxygen is present not only in organic compounds but also as free water (up to $30 \mathrm{wt} \%$ of the pyrolytic BO). Therefore, catalytic deoxygenation or co-processing upgrading [4] must be performed to convert the $\mathrm{BO}$ into valuable fuels. To promote these reactions, micro/mesoporous catalysts based on various mono/bi-metallic or sulfide active phases were screened [5,6]. Despite the better performances of noble metals (such as Pt, Pd or Ru), Ni/Alumina-based catalysts $[7,8]$ are often preferred because of quite good performances, resistance to poisons $[9,10]$ and their much lower cost which make them suitable for an industrial process.

Nevertheless, due to the high reactivity of pyrolytic BO compounds such as carbonyls and carbohydrates, deoxygenation reactions are in competition with condensation and oligomerization reactions [4, 11]. For instance, using a continuous reactor, Venderbosch et al. [11, 12] and Elliott et al. [13] evidenced the competition between the hydroconversion (HDC) pathways and the production of macromolecules which are readily observed from $175^{\circ} \mathrm{C}$. Wang et al. even observed heavy components during hydrogenation of woody bio-oil over $\mathrm{Ru} / \mathrm{TiO}_{2}$ catalyst at even lower temperature $\left(120^{\circ} \mathrm{C}-160^{\circ} \mathrm{C}\right)$ [14]. These side reactions are favored in absence of catalyst and hydrogen. Nevertheless, the targeted HDC reactions require such temperatures ranges. The production of high molecular weight compounds is detrimental to the process because it leads to an extensive plugging of the reactor and catalyst deactivation in addition to lower yields into valuable deoxygenated compounds. This is a process limitation which still needs an indepth comprehension before any industrial scale-up. Due to the BO complexity, the presence and growth of macromolecules is not easily characterized but SEC (or GPC) [37 = 15] and NMR/HSQC analyses [16-18] are sometimes used to reveal the macromolecule aromatic structures. Nevertheless, from a chemical point of view, the increase of the BO molecular weight is better described during storage conditions (BO aging). Then, periodic tracking [19-21] of either some macroscopic properties (such as pH or viscosity) or the 
molecular composition (such as the carbonyl and sugar titrations) bring the identification [22, 23] of reactions like esterification, aromatic condensation or acetylation leading to macroscopic precursors.

To limit those undesirable reactions, the $\mathrm{BO}$ can be stored below $0^{\circ} \mathrm{C}$ (preferably below $-15^{\circ} \mathrm{C}$ ) [21] or diluted in a solvent [24]. Some studies tried to mimic the positive effect of non-polar [25, 26] or polar [27-29] (oxygenated) solvents during the BO upgrading to dilute or convert macromolecules precursors. Another strategy is the multi-steps hydroconversion [29, 30] which converts macromolecules precursors at low temperatures (from 100 to $200^{\circ} \mathrm{C}$ ) and is followed by a deep deoxygenation at higher temperatures (up to $350^{\circ} \mathrm{C}$ ). Nevertheless, the involved reactions are not fully described and literature is largely lacking of rationalization of the chemical mechanisms leading to these macromolecules.

Numerous studies deal with representative model molecules of BO composition which result from lignocellulose degradation during the pyrolysis step. Because of the high diversity and chemical complexity of oxygenated compounds in a BO, it is mandatory to consider at least a mixture of representative compounds even if very few studies were proposed in the literature. During previous works performed by our group [31, 32], the catalytic hydroconversion of D-glucose and furfural was investigated and evidenced a fast and large production of macromolecules even at $200^{\circ} \mathrm{C}$. Those structures were proven to arise from furanic (e.g. furfural, 5-HMF) and aromatic (e.g. 1,2-benzenediol) compounds that were extensively produced by D-glucose dehydration and furfural hydrolysis. The conversion of single and mixed model molecules was studied using a multi-technique characterization strategy of liquid effluents (SEC, ${ }^{13} \mathrm{C}$ NMR, GC and HPLC) allowing the description of reaction pathways. By this mean, the beneficial effect of guaiacol for preventing macromolecules formation was demonstrated. Besides those studies, the description of the macromolecules production during a real BO hydroconversion is still needed. Therefore, in the present work, the catalytic hydroconversion of two feeds is investigated: the first one involves only a wood residues pyrolytic BO while the second one includes an addition of $50 \%$ of guaiacol in the same BO feed. This ratio was chosen after being compared with a $25 \%$ guaiacol/BO ratio which revealed the same trends that are exacerbated during the hydroconversion of bio-oil/guaiacol (50/50 wt\%) mixture (SI, Fig. S4 \& S5).

\section{Experimental Section}

\subsection{Experimental set-up}

The bio-oil (BO) under investigation was produced from the fast pyrolysis of solid residues at $480^{\circ} \mathrm{C}$ by VTT research center in 2013 on their industrial-representative pilot plant. Table 1 compares some macroscopic analysis of BOs from the literature with the characteristics of the one used in this study. The BO characteristics are well within the typical range of fast pyrolysis bio-oils which was stored at $-20^{\circ} \mathrm{C}$ for limiting the aging effects [21, 22]. Guaiacol (GUA) was purchased from Acros Organics (99+\% purity) and was used as received. Finally, a proprietary $\mathrm{NiMo} / \mathrm{Y}-\mathrm{Al}_{2} \mathrm{O}_{3}$ catalyst displaying hydrothermal resistance was supplied by Axens. Before each reaction, fresh catalyst was crushed and sieved to particle size from 1 to $2 \mathrm{~mm}$ and was reduced using a hydrogen flow (0.30 $\mathrm{m}^{3} \cdot \mathrm{h}^{-1}$ ) at atmospheric pressure and $400^{\circ} \mathrm{C}$ during $2 \mathrm{~h}$. This catalyst develops 0.33 and $0.1 \mathrm{~cm}^{3} \cdot \mathrm{g}^{-1}$ of mesoporous and macroporous volumes respectively.

All catalytic reactions were carried out in an isothermal $500 \mathrm{~cm}^{3}$ stainless steel autoclave equipped with an electromagnetic driven stirrer (Rushton impeller). For each run (schematized experimental procedure is reported in Figures S1), $150 \mathrm{~g}$ of feed was introduced followed by $15 \mathrm{~g}$ of freshly reduced catalyst transferred in an argon vessel avoiding any post-oxidation. Two feeds will be considered: either $150 \mathrm{~g}$ of $\mathrm{BO}$ or $75 \mathrm{~g}$ of BO plus $75 \mathrm{~g}$ of GUA (mixture referred to BO+GUA). Considering non-catalytic reactions (investigated in SI, section 3.3.), $30 \mathrm{~g}$ of glass balls were introduced (2 $\mathrm{mm}$ diameter) representing the same volume than the NiMo catalyst. The reactor was hermetically closed and purged by substituting air by $\mathrm{N}_{2}$ and finally by $\mathrm{H}_{2}$ (during hydroconversion tests). The initial pressure of hydrogen or nitrogen was set to 3.0 MPa before temperature increase.

The reaction temperatures ranged from 200 to $300^{\circ} \mathrm{C}$. In order to limit the catalytic reactions during the heating ramp ( $15 \mathrm{~min}$ to reach $\left.250^{\circ} \mathrm{C}\right)$, the feed was vigorously stirred $\left(1,200 \mathrm{tr}^{\mathrm{min}} \mathrm{m}^{-1}\right)$ only once the reaction temperature was reached. Stirring was maintained during cooling down. Hydrogen addition was set to maintain a constant total pressure of $13 \mathrm{MPa}$ during the run. Considering those stirring rates and catalyst beads size, no external hydrodynamic limitations have been observed [31].

Once the reaction time was reached, $\mathrm{H}_{2}$ introduction was stopped and the reactor was quickly cooled down to room temperature (10 min to cool down from 300 to $100^{\circ} \mathrm{C}$ ). Then, gaseous, liquid and solid products were totally recovered and separately analyzed. Gases were collected using an auxiliary vessel and sampled in vacuum TEDLARß bags for subsequent off-line gas chromatography 
(GC-FID/TCD) analysis. While the reactor was purged by nitrogen and unlocked, the catalytic basket was removed. The liquid phases and the solid residues were separated by centrifugation at 4,000 tr. $\mathrm{min}^{-1}$ during $20 \mathrm{~min}$. Subsequently, aqueous and organic phases were placed in a separator funnel referred respectively as "aqueous phase" and "organic phase". The recovered catalyst was washed using a Thermo Scientific ${ }^{\mathrm{TM}}$ Dionex $^{\mathrm{TM}}$ (ASE 150) extractor heated at $60^{\circ} \mathrm{C}$ and under a $10 \mathrm{MPa}$ acetone pressure. The catalyst and the solid residues were dried at $70^{\circ} \mathrm{C}$ under atmospheric pressure during $12 \mathrm{~h}$. Acetone was used as a washing solvent also to recover remaining products in the reactor and the impeller and was further removed by a vacuum rotary evaporator. The obtained liquid phase will be referred as "washed phase". The low experimental losses and the good repeatability contribute to reliability of our study (SI, Fig. S2 and S3).

\subsection{Analysis}

In order to determine the carbon balance, a Thermo Scientific ${ }^{\mathrm{TM}}$ FLASH 2000 was used to analyze the elemental carbon deposition (CHONS). Grinded solid samples were injected twice in an oven set at $950^{\circ} \mathrm{C}$ where $\mathrm{CO}_{2}$ was formed. An on-line TCD detector quantified this component and calculated the sample corresponding carbon equivalent. Every six samples, the analyzer was controlled by a BBOT (2,5-Bis(5-tert-butyl-benzoxazol-2-yl)thiophene) standard.

Gases were analyzed by GC (Agilent 7890A) equipped with a Flame lonization Detector (FID) and two Thermal Conductivity Detectors (TCD). Three parallel columns were used: HP-Plot Q (30 m x $0.32 \mathrm{~mm}$ i.d $\times 20 \mu \mathrm{m})$, HP-Plot $5 \mathrm{~A}(30 \mathrm{~m} \times 0.32 \mathrm{~mm}$ i.d $\times 1$ $\mu \mathrm{m})$ and PONA $(50 \mathrm{~m} \times 0.2 \mathrm{~mm}$ i.d $\times 0.5 \mu \mathrm{m})$ to get a complete analysis of all the gases. The carrier gas was helium. Standards were periodically injected for alkanes ( $\mathrm{C} 1$ to $\mathrm{C} 6), \mathrm{CO}, \mathrm{CO}_{2}, \mathrm{~N}_{2}$ and $\mathrm{H}_{2}$ quantification. The oven temperature program ranged from 30 to $200^{\circ} \mathrm{C}$ at a rate of $20^{\circ} \mathrm{C} \cdot \mathrm{min}^{-1}$.

Liquid effluents were analyzed by GC (AGILENT-6890N) with a Flame lonization Detector (FID) and a PONA (50 m x $0.2 \mathrm{~mm}$ i.d x 5 $\mu \mathrm{m}$ ) column. The vaporization temperature was $280^{\circ} \mathrm{C}$, the oven temperature program ranged from 100 to $250^{\circ} \mathrm{C}$ at a rate of $5^{\circ} \mathrm{C} . \mathrm{min}^{-}$ 1 . For each identified compounds, quantification was performed with guaiacol as an external standard and Effective Carbon Number method (ECN) was used to estimate FID response factors for oxygenates [33]. The GC/MS analysis was conducted with a Thermo Trace GC/MS equipped with the same columns and program than the GC/FID analysis. The mass analyzer is a simple quadrupole with an electron ionization ion source at $70 \mathrm{eV}$. The products were identified using the NIST library (2009).

Water content in liquid effluents was measured by a Karl Fischer (KF) Mettler Toledo V20. For every sequence, a calibration procedure with a Fluka Hydranal water standard 1.0 in methanol was performed. Each value indicated in this study corresponds to average of three measurements.

Soluble macromolecules contained in liquid effluents were analyzed by size exclusion chromatography (SEC) by a Waters system (Alliance). The system was constituted by four columns in series $(7.8 \times 300 \mathrm{~mm})$ containing $5 \mu \mathrm{m}$-particle size with porosity ranging from 10 to $1,000 \mathrm{~nm}$. During a typical analysis, $50 \mathrm{mg}$ of sample was diluted in $10 \mathrm{ml}$ of THF and injected into the column. Run were performed at $30^{\circ} \mathrm{C}$ (columns temperature) during $49 \mathrm{~min}$. Two detectors were used: a refractive index-detector and a UV-detector (set to three wavelengths: 214,254 and $280 \mathrm{~nm}$ ). Tetrahydrofuran was used as mobile phase $\left(1 \mathrm{~cm}^{3} \cdot \mathrm{min}^{-1}\right)$. Standard polystyrene mixtures having various molecular weights were used for calibration at the beginning of each new sequence and correspond to a Polystyrene (PS) molecular weight range from 160 to $5,000 \mathrm{~g} \cdot \mathrm{mol}^{-1}$. All signals were normalized following Equation 5 further presented.

In addition, liquid state quantitative ${ }^{13} \mathrm{C}$ NMR analysis were performed at $20^{\circ} \mathrm{C}$ on an AVANCE III Bruker $600 \mathrm{MHz}(14.1 \mathrm{~T})$ equipped with a $5 \mathrm{~mm}$ Z-gradient $\mathrm{BBI}$ probe and using inverse gated decoupling pulse sequence (zgig) with Spectral width: $42 \mathrm{kHz}$; Sweep Width 01 (center): $15 \mathrm{kHz}$; FID size: $65 \mathrm{~K}$; time between pulses (D1+AQ: $5.76 \mathrm{~s}$; All spectra were obtained after 1024 scans (acquisition time $1 \mathrm{~h} 30$ ) and were referenced to deuterated tetrahydrofuran (THF-d8). For each analysis, $0.05 \mathrm{~mL}$ of sample was diluted in $0.45 \mathrm{~mL}$ of THF-d8 without any relaxant. Quantification of the functional groups present in each sample was determined after baseline correction by integrating over characteristic regions using TopSpin 3.0 software. Intensities over defined chemical shift windows were integrated to quantify selected $C$ structures; $10-55$ ppm $\left(C-C_{\text {alkyl }}\right), 55-60$ ppm (C-methoxyl), 60-90 ppm $\left(C_{\text {alkyl }}-0\right.$ 
including carbohydrates), 90-165 ppm (C-aromatic), 165-220 ppm (C-carbonyl in carboxylic acids, esters, amides, ketones and aldehydes). Aromatic carbons will be discriminated between 90-142 ppm (Car-C and Car-H) and 142-165 ppm (Car-O). The peaks corresponding to guaiacol were not integrated. An example of ${ }^{13} \mathrm{C}$ spectrum for the starting bio-oil and bio-oil with $50 \%$ guaiacol after conversion are given in supplementary material (SI Fig. S24 \& S25).

Textural analyses of the fresh and used catalyst were performed by nitrogen physisorption Autopore4 and $\mathrm{Hg}$ porosimetry Micromeritics ASAP2420 equipment using ASTM D3663-03 method. The catalysts were additionally analyzed by X-Ray diffraction (XRD) using a PANalytical XPert pro endowed with a copper anode (Ka1 = $1.5406 \AA$ ). The XRD patterns were measured for the catalyst powder in a range of $2 \theta$ between 5 à $72^{\circ}$ (step size $0.033^{\circ}, 500 \mathrm{~s}$ ). The detector was set to scanning mode at $2.122^{\circ}$. Scherrer's equation was used in order to calculate the size of $\mathrm{Ni}^{0}$ crystallites prior and after reaction. Finally, TEM analyses were performed with a JEOL 2010F microscope in STEM-HAADF mode (probe size $0.7 \mathrm{~nm}$ ). Samples were grinded and dispersed in ethanol with ultra sound. A drop of solution was deposited on a holey carbon copper grid. Further drying, the grid was introduced into the TEM.

\subsection{Calculation of the mass balance, carbon balance, guaiacol conversion and normalized SEC-signals}

Equation 1: mass balance

Experimental mass loss (expressed in weight $\%)=\frac{\left(\mathrm{m}_{\text {liquid }}+\mathrm{m}_{\text {gases }}+\mathrm{m}_{\text {catalyst }}\right)_{\text {in }}-\left(\mathrm{m}_{\text {liquid }}+\mathrm{m}_{\text {gases }}+\mathrm{m}_{\text {catalyst }}+\mathrm{m}_{\text {residues }}\right)_{\text {out }}}{\left(\mathrm{m}_{\text {liquid }}+\mathrm{m}_{\text {gases }}+\mathrm{m}_{\text {catalyst }}\right)_{\text {in }}} \times 100$

Equation 2: guaiacol conversion

$$
X_{\text {gua }}=\frac{n_{\text {gua }, 0}-n_{\text {gua }}}{n_{\text {gua }, 0}}
$$

With:

- Xgua : guaiacol conversion rate

- $\quad \mathrm{n}_{\text {gua }, 0}$ and $\mathrm{n}_{\text {gua }}$ : guaiacol molar amount respectively at the beginning and the end of the reaction [mol]

Equation 3: carbon equivalent mass balance during guaiacol conversion

$$
m_{C, \text { gua }}=\left(n_{\text {gua }, 0}-n_{\text {gua }}\right) \times W \text { gua } \times \text { wt } \% \text { Cgua }
$$

With:

- $\quad \mathrm{m}_{\mathrm{C}, \text { gua }}$ : mass of carbon equivalent from the guaiacol conversion [g]

- $\mathrm{W}_{\text {gua }}$ : guaiacol molecular mass $=124.1 \mathrm{~g} \cdot \mathrm{mol}^{-1}$

- $\mathrm{wt} \% \mathrm{C}_{\text {gua }}$ : weight carbon content in guaiacol $=67.7 \mathrm{wt} \%$

Equation 4: guaiacol products' selectivity

$$
Y_{j}=\frac{m_{C j}}{m_{C, g u a}} \times 100
$$

With:

- $\quad Y_{j}$ : selectivity to the "j" guaiacol product

- $\mathrm{m}_{\mathrm{C}, \mathrm{j}}$ : mass of carbon equivalent in the compound $\mathrm{j}[\mathrm{g}]$

In order to compare SEC analyses with various water content liquid phases, raw signals will take into account the water dilution. Thus, signals will be presented as:

Equation 5: Nomalized SEC signal $=\frac{\text { Raw signal }}{100 \mathrm{mg}} \times \frac{1}{1-\text { Water content }- \text { Guaiacol content }}$

$$
=\frac{\text { Raw signal }}{100 \mathrm{mg}} \times \frac{1}{\text { Organic content }}
$$

With:

- Raw signal / 100: Raw signal (RI or UV $254 \mathrm{~nm}$ ) normalized to a $100 \mathrm{mg}$ sample [mg ${ }^{-1}$ ]. 
- Water content: weight water content in the liquid phase [-].

- Guaiacol content: weight guaiacol content remaining in the liquid phase (for BO+GUA experiments) [-].

- Organic content: weight organic content in the liquid phase [-].

- To facilitate the following discussion, Fig. S17 in SI gives an overview of the main analytical results and conclusions.

\section{Results and Discussion}

3.1. Effect of the reaction time on the bio-oil and bio-oil/guaiacol catalytic hydroconversion

In this part, the effect of reaction time on the catalytic hydroconversion of $\mathrm{BO}$ is investigated concurrently with $\mathrm{BO}+\mathrm{GUA}$. Reaction temperature was set at $250^{\circ} \mathrm{C}$ and various reaction times were used ranging from $\mathrm{t}_{0}$ (just reaching $250^{\circ} \mathrm{C}$ ) to $180 \mathrm{~min}$.

Mass balances are reported in supporting information (SI, Fig. S6.). As observed by others [5, 6], two liquid phases were recovered in addition of the gas phase. The analysis of this gaseous fraction shows mainly $\mathrm{CO}_{2}$ and $\mathrm{CO} ; \mathrm{CO}_{2}$ decreased in favor of $\mathrm{CH}_{4}$ and $\mathrm{CO}$ for BO+GUA mixture (SI, Fig. S7). No extensive solid production was observed but a progressive and significant coke deposit in the catalyst porosity was noticed, with a maximum coke deposition reaching $13.1 \mathrm{wt} \%$ after a $3 \mathrm{~h}$ BO conversion in absence of guaiacol. For both $\mathrm{BO}$ and $\mathrm{BO}+\mathrm{GUA}$, a heavy organic phase has been obtained representing up to $74.9 \mathrm{wt} \%$ of the mass balances (from the BO+GUA hydroconversion during $3 \mathrm{~h}$ ). When guaiacol was added, the viscosity of the organic phase was significantly decreased, enabling a better experimental mass balance (loss lower than $5 \mathrm{wt} \%$ for all cases). It is interesting to note that BO released an extensive quantity of gas mainly composed by $\mathrm{CO}$ and $\mathrm{CO}_{2}$ suggesting the importance of decarbonylation and decarboxylation reactions contrary to $\mathrm{BO}+\mathrm{GUA}$ feed. Gas phase analysis provided the remaining amount of hydrogen. By difference with the amount of introduced hydrogen during the test, the consumption is calculated and reported in Figure $1[\mathrm{~A}]$ for both $\mathrm{BO}$ and $\mathrm{BO}+\mathrm{GUA}$ hydroconversion experiments. During the first hour, the consumption was multiplied by 2.7 and 1.8 respectively (corresponding to a consumption of 16.7 and 20.9 mol\% of the introduced hydrogen). Further, only a $12.1 \mathrm{~mol} \%$ growth was observed during the BO hydroconversion confirming the importance of the first minutes of the process. $\mathrm{Th} \mathrm{H}_{2}$ consumption significantly increased in the presence of guaiacol even after $1 \mathrm{~h}$ of reaction. This growth could be explained by the conversion of guaiacol, nevertheless, after $3 \mathrm{~h}$, only $3 \mathrm{~mol}$ \% of the $\mathrm{H}_{2}$ consumption can be directly ascribed to the production of 1,2-benzenediol. In our operating conditions, only this product was detected from the guaiacol hydroconversion (SI, Fig. S9.). This indicates that the increase of $\mathrm{H}_{2}$ consumption after 1 $h$ of reaction is not only due to guaiacol conversion.

Concerning the BO+GUA feed, the evolution of the guaiacol conversion (quantified by GC-FID) is illustrated by Figure 1 [B]. This Figure also reports the ratio between GC-quantified 1,2-benzenediol carbon equivalent and carbon equivalent released from guaiacol conversion (Eq. (3) and (4)). During the reactor heating ramp, $38.9 \%$ of the guaiacol was converted, nevertheless, only $0.3 \mathrm{wt} \%$ of the released carbon was actually transformed into 1,2-benzenediol. From to to $30 \mathrm{~min}$, more than $47.3 \%$ of guaiacol was converted but less than $0.4 \mathrm{wt} \%$ was ascribed to 1,2-benzenediol. Finally, above $30 \mathrm{~min}$ reaction, the guaiacol conversion significantly decreased (as shown by a higher GC-FID quantification of guaiacol) while 1,2-benzenediol production increased. This is consistent with the higher production of $\mathrm{CH}_{4}$ above $30 \mathrm{~min}$ of reaction as methane comes mainly from demethylation of guaiacol to benzenediol (SI, Fig. S7.). This trend has already been described by Patil et al. [34] and also observed during our previous study [32] dealing with the catalytic HDC of BO model compounds mixtures for instance D-glucose and guaiacol. Under the same operating conditions, we concluded that guaiacol was readily reacting with sugar type macromolecules but was converted through HDO pathways after 30 min of reaction. The reactions between guaiacol and macromolecules until $30 \mathrm{~min}$ did not consume hydrogen as shown in Figure 1. In addition, due to the moderated temperature $\left(250^{\circ} \mathrm{C}\right)$, the conversion of guaiacol by cracking reactions was not considered [35]. Thus, the carbon balance is an efficient tool to assess the conversion of guaiacol between well-known HDC conversion pathways [36, 37] (i.e. GC-quantified products) and macromolecules precursors stabilization pathways [32]. This macroscopic analysis will be herein completed by SEC and ${ }^{13} \mathrm{C}$ NMR analysis.

Figure 2 represents the normalized SEC analysis (following eq. (5)) of the raw BO and the recovered liquid effluents. Graphs [A] and [B] correspond to the BO conversion respectively analyzed with RI and UV-254 nm detectors. These two analyses are also reported in Graphs [C] and [D] for the conversion of the BO+GUA mixture. Thus, the BO was initially constituted by heavy compounds not larger than 3,000 g.mol ${ }^{-1}$ PS eq.. Thanks to the UV-254 nm detector (Figure 2 [B]), the contribution of unsaturated compounds like aromatic and carbonyl functions can be assessed as a significant part of those heavy structures. Nevertheless, due to the difference 
between profiles of $\mathrm{BO}$ continuum shape and of the effluents ones, it is impossible to directly compare their compositions. Regarding the BO HDC (Figure 2, Graphs $[A]$ and $[B]$ ), the signals confirm the presence of macromolecules that spread the molecular weight domain up to 8,000 g.mol ${ }^{-1} \mathrm{PS}$ eq.. This suggests the importance of the first minutes of reaction where homogeneous catalyzed reactions (refer to t0) such as dehydration, aldolization/crotonization [31, 32] are favored in acidic medium (See SI section 3.5 dedicated to the effect of the catalyst). In the same way, UV-254 nm detector did not only indicate the presence of aromatic and carbonyl compounds constituting the macromolecules but also the formation of compounds with molecular weight higher than 400 g. $\mathrm{mol}^{-1} \mathrm{PS}$ eq. above $30 \mathrm{~min}$ of reaction. Aqueous phases (dotted lines) presented signals which did not involve macromolecules greater than 1,000 g.mol ${ }^{-1}$ PS eq.. In addition, SEC clearly indicated a decrease of the normalized signals suggesting the conversion or the migration of some lighter macromolecules from the aqueous to the organic phase. The fast production and the stability of macromolecules at this temperature is also observed during the HDC of BO+GUA. SEC-RI analysis (Figure 2 [C] and [D]) confirms the production of 1,2-benzenediol (160 g.mol ${ }^{-1}$ PS eq.) previously detected by GC (Figure 1 [B]) after $1 \mathrm{~h}$ of reaction. Regarding Figure $2[\mathrm{~A}]$ and $[\mathrm{B}]$, those macromolecules were obviously quite different (but still stable at this temperature) since their higher molecular weight did not go beyond 3,000 g.mol ${ }^{-1} \mathrm{PS}$ eq. According to the previous model molecule conversion study [32], guaiacol limited the macromolecules growth, not only by a dilution effect, but also by reacting with the precursors coming from glucose and furfural. To go further on the effect of guaiacol addition and to evaluate the chemical reaction effect versus the physical dilution effect, additional experiments were performed with six different molecules (SI, Figure S10). The use of oxygenated compounds like anisole, phenol, heptanol or 1,2-benzenediol led, as guaiacol, to decrease macromolecules formation while tetralin performed the worst limitation. This results suggest that, as expected, tetralin interferes differently with macromolecules precursors but also points out the weaker solvating properties towards oxygenated organic compounds in our conditions $\left(1 \mathrm{~h}, 250^{\circ} \mathrm{C}\right)$. All the molecules used were more or less converted during the experiments but it can be noted that phenolics ones and especially guaiacol, and 1,2-benzenediol, were the most converted.

The beneficial effect of guaiacol had also consequences on the textual properties of used catalysts. Figure 2 [E] reports the evolution of the pore size distribution and volumes of used catalysts respectively from BO and BO+GUA HDC. In absence of guaiacol, the predominance of macromolecules observed in Figure $2[A]$ and $[B]$ resulted in the deposition of carbon from 4.2 to 8.4 wt\% between $\mathrm{t}_{0}$ and $30 \mathrm{~min}$ of reaction. This value rose up to $13.1 \mathrm{wt} \%$ after $3 \mathrm{~h}$ of reaction, with a coke preferentially located into the mesopores (pore diameters ranging from 2 to $50 \mathrm{~nm}$ ) which lose half of their initial volume. The bimodal pore size distribution presented in SI (Fig. S11) illustrates the impact of the first $30 \mathrm{~min}$ of the reaction. In parallel to the macromolecule production decrease, the guaiacol addition lowers the carbon deposition to $10.9 \mathrm{wt} \%$ after $3 \mathrm{~h}$ of reaction. In this case, the volume of the macropores only decreased from 0.21 to $0.15 \mathrm{~cm}^{3} . \mathrm{g}^{-1}$ (-28.6\%) for BO HDC. With both feeds, XRD analysis did not allow the detection of boehmite (AIOOH) crystallites suggesting the protection [32] of alumina carrier against carrier acidic species and water. XRD and STEEM-HAADF (SI, Fig. S12 and S13) analyses also revealed the presence of $\mathrm{Ni}$ and Mo sintered crystallites (about $20 \mathrm{~nm}$ after $1 \mathrm{~h}$ after BO and BO+GUA conversion). Nevertheless, those crystallites were too scattered to be statistically representative of the metal dispersion of the used catalysts.

Finally, to better understand the chemical reaction occurring during the hydroconversion, liquid state ${ }^{13} \mathrm{C}$ NMR analysis has been performed and compared to initial BO (SI, Fig. S24). Figure $3[\mathrm{~A}]$ and $[\mathrm{B}]$ report carbon distributions in the liquid products (organic and aqueous phases) obtained after $\mathrm{BO}$ and $\mathrm{BO}+\mathrm{GUA} \mathrm{HDC}$ at different reaction times. For $\mathrm{BO} \mathrm{HDC}$, the organic phase compositions were function of the reaction time and revealed the increase of aromatic carbons contribution (especially $\mathrm{C}-\mathrm{C}$ and $\mathrm{C}-\mathrm{H}$ ). This observation suggests the occurrence of deoxygenating (demethoxylation, dehydroxylation) and cyclization reactions. Overall, the aromatic carbons represented more than 60 at. $\%$ after $3 \mathrm{~h}$ of reaction concomitantly to aromatic compound observed by SEC-UV 254 $\mathrm{nm}$ results (Figure $2[\mathrm{~B}]$ ). This composition is also in accordance with the elemental ratios reported in the Van Krevelen Diagram (SI, Fig. S8) where organic phases were located in the lignin area. In parallel, the aqueous phases analysis revealed an increase of the aliphatic carbons ( $\mathrm{C}-\mathrm{C}$ and $\mathrm{C}-\mathrm{O}$ ). Moreover, the high concentration of carbonyls species suggests the formation of polar compounds more soluble in water than aromatic compounds.

Considering BO+GUA products analysis (Figure $3[\mathrm{~B}]$ ), ${ }^{13} \mathrm{C}$ NMR spectral contributions belonging to remaining guaiacol (at 55.8 , $110.9,114.7,120.2,121.5,145.7,146.7$ ppm) have been subtracted from the different integrated area (SI, Fig. S25). As discussed previously, the production of guaiacol derivatives such as 1,2-benzenediol in the organic effluent (Figure 1 [B]) led to an increase of the $\mathrm{C}_{\text {aromatic }}-\mathrm{O}$ contribution which represents 8.9 atomic\% (or at.\%) after $3 \mathrm{~h}$ of reaction. This observation is also true for the $\mathrm{C}-\mathrm{OMe}$ carbons including guaiacol derivatives (such as anisole groups). As observed by the $\mathrm{H}_{2}$ consumption (Figure 1 [A]), the aliphatic carbons significantly increased up to 29.4 at.\% suggesting an improvement of HDO reactions compared to the BO HDC. While the 
organic phases were composed by aromatic compounds, the aqueous phases contained mainly low molecular mass compounds with aliphatic carbons (C-C and C-O) shaping the low molecular mass compounds (Figure 2 [C] and [D]).

During the hydroconversion involving D-glucose, furfural and guaiacol, we observed reactions between guaiacol and macromolecules precursors which effectively avoid the macromolecules formation [32]. This study confirms the role of guaiacol reactivity while converted with BO macromolecules precursors including carbohydrates type components [18, 38]. This phenomena was mainly observed before $1 \mathrm{~h}$ and below $250^{\circ} \mathrm{C}$ as regard to the fast reaction kinetics involved on the macromolecules production (Fig. 2 [A] and $[\mathrm{B}])$. To compare this trend, the second part of this paper deals with the effect of the temperature following the same methodology.

\subsection{Effect of the reaction temperature on the bio-oil and bio-oil/guaiacol catalytic hydroconversion}

Following the previous analytical strategy, the $1 \mathrm{~h}$ conversion of both feeds (BO and $\mathrm{BO}+\mathrm{GUA}$ ) at 200,250 and $300^{\circ} \mathrm{C}$ will be presented herein. As previously shown at $250^{\circ} \mathrm{C}$, those experiments led mainly to the production of liquid in the $200-300^{\circ} \mathrm{C}$ range. Mass balances (SI, Fig. S14) confirmed that BO conversion produced a larger quantity of gas phase detrimentally to liquid phase when temperature increased. Gas phase analysis ( $\mathrm{SI}$, Fig. S15) showed a slight increase of $\mathrm{CO}$ and $\mathrm{CH}_{4}$, detrimental to $\mathrm{CO}_{2}$, by increasing the temperature; this increase is more pronounced in the case of the presence of guaiacol. $\mathrm{H}_{2}$ consumption has been calculated from the gas analysis (Figure $4[\mathrm{~A}]$ ). While temperature increases, $\mathrm{H}_{2}$ consumption decreases. As an autoclave reactor is used, $\mathrm{H}_{2}$ partial pressure varies according to the temperature, nevertheless, the $\mathrm{H}_{2}$ consumed/introduced ratio increases except for $\mathrm{BO} \mathrm{HDC}$ at $300^{\circ} \mathrm{C}$. This phenomena is due to production of macromolecules and coke formation on the catalyst evidenced by the decrease of the porosity (Fig. 5). The decrease was significantly lower in the case of the mixture conversion $(B O+G U A)$. At $300^{\circ} \mathrm{C}$, $8 \%$ of the $\mathrm{H}_{2}$ consumption can be directly ascribed to the production of 1,2-benzenediol. As discussed previously for the effect of reaction time, guaiacol addition in the reactant mixture enhances catalyst reactivity, and its conversion into HDO products is favored $[31,32]$. Once again, the guaiacol conversion and the ratio between GC-quantified guaiacol products (1,2-benzenediol) expressed in carbon equivalent (Eq. (4)) is reported herein in Figure 4 [B]. While the conversion of guaiacol was quite constant in function of the HDC temperature, 1,2-benzenediol production (following $\mathrm{CH}_{4}$ reported in SI, Figure S13) grew up to 6.0 wt\% of the converted guaiacol at $300^{\circ} \mathrm{C}$. This $\mathrm{H}_{2}$ consuming reaction was previously observed [32] during the conversion of the model molecules mixture at this temperature. Although guaiacol readily reacted with macromolecules coming from D-glucose and furfural, we also observed that guaiacol $\mathrm{HDO}$ was promoted at $300^{\circ} \mathrm{C}$ as it was expected thanks to the published works [36, 37].

As observed at $250^{\circ} \mathrm{C}$ in Figure 2, up to $8,000 \mathrm{~g} \cdot \mathrm{mol}^{-1} \mathrm{PS}$ eq. macromolecules were formed in the organic phases by SEC-RI/UV analysis (Figure $5[\mathrm{~A}]$ and $[\mathrm{B}]$ ). From 200 to $300^{\circ} \mathrm{C}$, an increase of the signal ranging from 300 to 2,000 g.mol ${ }^{-1} \mathrm{PS}$ eq. and a decrease of higher components was noticed. In that molecular weight range, the UV-254 nm detector (Figure 5 [B]) highlighted the growth of the normalized signal intensity suggesting the production of smaller aromatic macromolecules. Considering the decrease of the $\mathrm{H}_{2}$ consumption with temperature (Figure 4), the production of smaller macromolecules suggests the importance of hydrolysis reactions instead of hydrogenolysis reactions. Indeed, hydrolysis reactions were observed during the conversion of carbohydrates and derivatives conversion in acid-hydrothermal medium [31]. Again, those detrimental reactions were arising from the homogenous phase (SI section 3.5) and strongly affected the textural properties of the NiMo catalyst. The conversion of BO+GUA with temperature exhibits a similar behavior as the one observed at $250^{\circ} \mathrm{C}$. Despite the modification of the guaiacol conversion pathway observed at $300^{\circ} \mathrm{C}$ (Figure $4[\mathrm{~B}]$ ), the production of macromolecules was still limited to 2,000 g.mol ${ }^{-1} \mathrm{PS}$ eq. (Figure $5[\mathrm{C}]$ and [D]). This observation is also confirmed in the aqueous phases where no compound has been observed above 600 g.mol ${ }^{-1} \mathrm{PS} \mathrm{eq.}$.

The hydroconversion temperature has an impact on the reactivity (further described by ${ }^{13} \mathrm{C}$ NMR and SEC analysis) and thus the textural properties of catalysts are also modified regarding the evolution of BET and porous volumes of the used catalysts (Figure 5 [E]). The BO conversion led to an extensive coke deposition which mainly decreased the mesoporous volume of the catalyst and consequently $\mathrm{H}_{2}$ consumption stagnancy from 200 to $300^{\circ} \mathrm{C}$. In the case of the BO+GUA mixture hydroconversion, the textural properties are kept which is in line with the lower macromolecule production. Effectively, mesoporous volumes were quite preserved at $0.21 \mathrm{~cm}^{3} \cdot \mathrm{g}^{-1}$ (decrease of $36 \%$ of the mesopores volume compared to the fresh catalyst) and did not depend on the reaction temperature. This effect, ascribed to the guaiacol presence, follows the enhancement of the $\mathrm{H}_{2}$ consumption (Figure 4 [A]) and the low coke deposition even at $300^{\circ} \mathrm{C}$. Indeed, at this temperature, 12.8 and $10.5 \mathrm{wt} \%$ of coke was analyzed on the used catalysts after conversion of $\mathrm{BO}$ and $\mathrm{BO}+\mathrm{GUA}$ respectively. While $\mathrm{XRD}$ analysis did not reveal any boehmite formation, sintering of $\mathrm{Ni}^{0}$ crystallites 
was observed (size up to $30 \mathrm{~nm}$ ) during $\mathrm{BO}$ and $\mathrm{BO}+\mathrm{GUA}$ conversions at $300^{\circ} \mathrm{C} / 1 \mathrm{~h}$. Moreover, no large crystallites were observed by STEM afterwards.

To go further in the molecular description, liquid state ${ }^{13} \mathrm{C}$ NMR analysis was performed for both organic and aqueous effluents arising from BO (Figure $6[\mathrm{~A}]$ ) and $\mathrm{BO}+\mathrm{GUA}$ (Figure $6[\mathrm{~B}]$ ). Increasing the temperature during $\mathrm{BO}$ conversion enhances the concentration of aromatic carbons in the organic phase (Figure $6[\mathrm{~A}]$ ). Cyclisation reactions (without $\mathrm{H}_{2}$ consumption) into oxygenated aromatic compounds such as 1,2,3-benzenetriol has been previously reported during the dehydration of D-glucose into 5-HMF in the same operating conditions [30]. This observation is in agreement with the decrease of carbonyls compounds into the organic phase, as shown in Boscagli's study [7]. As observed during the model molecule conversion [30, 31] at $300^{\circ} \mathrm{C}$, the organic phase deoxygenation proceeds mainly by dehydration and cyclization reactions. Then $\mathrm{H}_{2}$ consumption remained low (Figure 4 [A]) and the organic phase tends to form a lignin-like structure (see Van Krevelen Diagram in Figure S16). For BO, we mainly observed aliphatic and carbonylic carbons in aqueous phase (Figure $6[A]$ ), suggesting the presence of water-soluble oxygenated compounds such as esters or carboxylic acids. In the same aqueous fraction, aliphatic $\mathrm{C}-\mathrm{O}$ decreased with the temperature increase.

Considering ${ }^{13} \mathrm{C}$ NMR analysis of organic phases arising from BO+ GUA (Figure $6[\mathrm{~B}]$ ), the evolution of the organic composition between 200 and $250^{\circ} \mathrm{C}$ was not significant. The large proportion of $\mathrm{C}_{\text {aliphatic }} \mathrm{O}$ carbon at $200^{\circ} \mathrm{C}(38.8$ at.\%) confirms their low

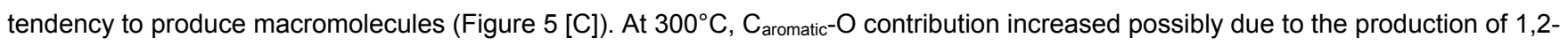
benzenediol from guaiacol while the aliphatic C-O decreased strongly compared to lower temperature. These results are in agreement with the $\mathrm{H}_{2}$ consumed to produce GC-quantified guaiacol products (Figure 4 [B]) and the SEC-UV $254 \mathrm{~nm}$ analysis (Figure $5[\mathrm{D}]$ ). This also confirms the production of 1,2-benzenediol which can further participate, as guaiacol, to the limitation of the macromolecule production [31]. This latter component is also solubilized into the aqueous phase (solubility: $0.44 \mathrm{~g} \cdot \mathrm{g}^{-1}$ of water at $20^{\circ} \mathrm{C}$ ) as indicated in SEC-UV $254 \mathrm{~nm}$ analysis (Figure 5 [D]). The global disappearance of carbonyls at high temperature is concomitant with the production of $\mathrm{CO}$ and $\mathrm{CO}_{2}$ from decarbonylation and decarboxylation reactions (SI, Fig. S15). As reported in our previous studies, those two gaseous compounds were mainly produced during the conversion of D-glucose under hydrothermal operating conditions into humins/macromolecules components.

These results bring new insights in regards to Venderbosch et al. [11,12] and Elliott et al. [13] studies on BO instability during the hydroconversion, as well as about solvent role in pilot scale. Processing BO at high temperature favored uncontrolled dehydration and cyclisation reactions from carbonyls and carbohydrates leading to macromolecules with aromatic structures [30]. Thanks to this systematic methodology and considering a representative BO model molecules mixture [32], we described the macromolecules formation by the fast reaction of guaiacol and/or its products, especially 1,2-benzenediol, with carbohydrates at low temperature. From ${ }^{13} \mathrm{C}$ NMR, SEC and elemental analysis, those macromolecules are supposed to be linked by $\mathrm{C}_{\mathrm{ar}}$-O ethers bonds (lignin-like) which are stable at low temperature but converted at higher temperature (see Figures $5[A-B]$ and Figure $6[A]$ ).

\section{Conclusions}

Despite the extended literature dealing with the catalytic hydroconversion of fast pyrolysis bio-oil (BO), the undesired macromolecule production depending on the process parameters still needs to be clarified. Because of the chemical complexity of the BO, we applied an analytical strategy characterizing both organic and aqueous effluents. The influence of the residence time and of the temperature on the nature of the products have also been investigated with a reliable experimental procedure.

While gaseous chromatographic analyses are not able to characterize macromolecules production arising during the $\mathrm{BO}$ conversion, SEC analysis highlight structures beyond 5,000 g.mol ${ }^{-1} \mathrm{PS}$ eq.. For the BO hydroconversion at $250^{\circ} \mathrm{C}$, macromolecules were produced in homogeneous phase and were further recovered in the organic phases. Those structures were particularly stable with reaction time since no conversion has been observed by SEC analysis. Nevertheless, elemental analysis and quantitative liquid state ${ }^{13} \mathrm{C}$ NMR indicated the production of deoxygenated species mostly composed of aromatic rings as well as deoxygenated aliphatic compounds. Those catalyzed reactions were enhanced at higher temperature despite the low hydrogen consumption. Thanks to the textural analysis of used catalysts, it was demonstrated that mesopores were particularly affected by this production unlike the experiments carried out in presence of guaiacol.

Effectively, the BO+GUA mixture hydroconversion showed enhanced hydrogen consumption that was consistent with the lower coking of the catalyst compared to the BO hydroconversion. As shown by SEC and GC analyses, guaiacol reacted with the macromolecules precursors and limited their production of high molecular mass molecules (up to 3,000 g.mol ${ }^{-1}$ PS eq. into the organic phases). This phenomenon was mainly observed at low temperature and short reaction time as guaiacol was not converted 
into its light usual hydroconversion products (1,2-benzenediol, phenol). At high temperature and/or long reaction time guaiacol was mainly converted into light aromatic compounds and contributed in a lesser extent to the macromolecule solubilization. As already demonstrated with model molecules, the positive role of guaiacol or some other oxygenated compounds like phenol, 1,2-benzenediol, anisole or heptanol for preventing the formation of undesired macromolecules is now confirmed in the case of a bio-oil hydroconversion. Therefore, in this case, the recycling of a fraction of the products into the reactor or the recycling of a well-chosen solvent would be highly desirable to improve the process.

\section{Acknowledgements}

Authors thanks for fruitful discussions A.-S. Gay, N. Charon, M. Rivallan and A. Le Masle. In addition, M. Ozagac is grateful to F. Neyret-Martinez, R. Comte, S. Sivault, F. Moreau, V. Lefebvre, I. Clémençon, F. Filali and J. Ouvry who performed the numerous analyses presented along this paper.

\section{Appendix A. Supplementary information}

Supplementary information (referred to $\mathrm{SI}$ ) related to this article can be found at ...

\section{References}

[1] A.V. Bridgwater, Review of fast pyrolysis of biomass and product upgrading, Biomass Bioenergy 38 (2012) 68-94.

[2] E. Furimsky, Catalytic hydrodeoxygenation, Appl. Catal. A 199 (2000) 147-190.

[3] A. Oasmaa, P. Peacocke, A Guide to Physical Property Characterisation of Biomass-derived Fast Pyrolysis Liquids, VTT Publications 731, Espoo, 2010.

[4] F. de Miguel Mercader, M.J. Groeneveld, S.R.A. Kersten, C. Geantet, G. Toussaint, N.W.J. Way, C.J. Schaverien, K.J.A. Hogendoorn, Hydrodeoxygenation of pyrolysis oil fractions: process understanding and quality assessment through coprocessing in refinery units, Energy Environ. Sci. 4 (2011), 985-997.

[5] J. Wildschut, PhD thesis, University of Groningen, 2009 (Netherlands)

[6] A. R. Ardiyanti, PhD thesis, University of Groningen, 2013 (Netherlands)

[7] C. Boscagli, K. Raffelt, T.A. Zevaco, W. Olbrich, T.N. Otto, J. Sauer, J.-D. Grunwaldt, Mild hydrotreatment of the light fraction of fast-pyrolysis oil produced from straw over nickel-based catalysts, Biomass Bioenergy 83 (2015) 525-538.

[8] A.R. Ardiyanti, M.V. Bykova, S.A. Khromova, W. Yin, R.H. Venderbosch, V.A. Yakovlev, H.J. Heeres, Ni-based catalysts for the hydrotreatment of fast pyrolysis oil, Energy Fuel 30 (2016) 1544-1554.

[9] E. Laurent, B. Delmon. Deactivation of a Sulfided NiMo/Al2O3 during the hydrodeoxygenation of Bio-Oils: Influence of a High Water Pressure. In: Studies in Surface Science and Catalysis Catalyst Deactivation. Proceedings of the 6th International Symposium, (Eds.: B. Delmon and Elsevier), 1994, 459-466.

[10] D. C. Elliott, K. L. Peterson, D. Muzatko, E. Alderson, T. Hart, G. G. Neuenschwander, The Effects of Trace Contaminants on Catalytic Processing of Biomass-Derived Feedstocks, Appl. Biochem. Biotechnol. 115 (2004) $807-825$.

[11] R.H. Venderbosch, H.J. Heeres, Pyrolysis oil stabilisation by catalytic hydrotreatment, in: Marco Aurelio Dos Santos Bernardes (Ed.), Biofuel's Engineering Process Technology, 2011, 385-410 (Rijeka).

[12] R.H. Venderbosch, A.R., Ardiyanti, J. Wildschut, A. Oasmaa, H.J. Heeres, Stabilisation of biomass derived pyrolysis oils, J. Chem. Technol. Biotechnol. 85 (2012) 674-686.

[13] D.C. Elliott, S.J. Lee, T.R. Hart, Stabilization of Fast Pyrolysis Oil: Post Processing, PNNL Report - 21549,2012 (Washington).

[14] H. Wang, S-J. Lee, M. V. Olarte, A. H. Zacher, Bio-oil stabilization by hydrogenation over reduced metal catalysts at low temperatures, ACS Sustain. Chem. Eng. 4 (2016) 5533-5545. 
[15] S. Kumar, J.-P. Lange, G. Van Rossum, S.R.A. Kersten, Liquefaction of Lignocellulose: Process Parameter Study To Minimize Heavy Ends, Ind. Eng. Chem. Res. 53 (2014) 11668-11676.

[16] M. Castellví Barnes, J.P. Lange, G. van Rossum, S.R.A. Kersten, A new approach for bio-oil characterization based on gel permeation chromatography preparative fractionation, J. Anal. Appl. Pyrol. 113 (2015) 444-453.

[17] R. Bayerbach, V.D. Nguyen, U. Schurr, D. Meier, Characterization of the water insoluble fraction from fast pyrolysis liquids (pyrolytic lignin): Part III. Molar mass characteristics by SEC, MALDI-TOF-MS, LDI-TOF-MS, and Py-FIMS, J. Anal. Appl. Pyrol. 77 (2006) 95-101.

[18] J. Joseph, M.J. Rasmussen, J.P. Fecteau, S. Kim, H. Lee, K.A. Tracy, B.L. Jensen, B.G. Frederick, E.A. Stemmler, Compositional Changes to Low Water Content Bio-oils during Aging: An NMR, GC/MS, and LC/MS Study, Energy Fuels. 30 (2016) 4825-4840.

[19] A. Oasmaa, E. Leppämäki, P. Koponen, J. Levander, E. Tapola, Physical characterisation of biomass-based pyrolysis liquids: Application of standard fuel oil analysis, (Eds.: VTT publications), 1997 (Espoo).

[20] A. Oasmaa, S. Czernik, Fuel Oil Quality of Biomass Pyrolysis Oils State of the Art for the End Users, Energy Fuels. 13 (1999) 914-921.

[21] A. Oasmaa, J. Korhonen, E. Kuoppala, An Approach for Stability Measurement of Wood-Based Fast Pyrolysis Bio-Oils, Energy Fuels. 25 (2011) 3307-3313.

[22] J.P. Diebold, A Review of the Chemical and Physical Mechanisms of the Storage Stability of Fast Pyrolysis Bio-Oils, (Eds.: NERL report), 2000, (Battelle).

[23] D. Chen, J. Zhou, Q. Zhang, X. Zhu, Evaluation methods and research progresses in bio-oil storage stability, Renewable Sustainable Energy Rev. 40 (2014) 69-79.

[24] A. Oasmaa, E. Kuoppala, J. F. Selin, S. Gust, Y. Solantausta, Fast Pyrolysis of Forestry Residue. 3. Storage Stability of Liquid Fuel, Energy Fuels. 18 (2004) 1578-1583.

[25] X. Xu, C. Zhang, Y. Liu, Y. Zhai, R. Zhang, In situ hydrodeoxygenation upgrading of pine sawdust bio-oil to hydrocarbon biofuel using Pd/C catalyst, Chemosphere, 93 (2013) 652-660.

[26] H. Li, S. Xia, P. Ma, Upgrading fast pyrolysis oil: solvent-anti-solvent extraction and blending with diesel, Energy Convers. Manage. 110 (2016) 378-385.

[27] K.M. Isaa, C.E. Snape, C. Uguna, W. Meredith, H. Deng, Hydrothermal Conversion Of Biomass. II. Conversion Of Wood, Pyrolysis Oil, And Glucose In Hot Compressed Water, J. Anal. Appl. Pyrol. 119 (2016) 180-188.

[28] X. Xu, C. Zhang, Y. Zhai, Y. Liu, R. Zhang, Upgrading of Bio-Oil Using Supercritical 1-Butanol over a Ru/C Heterogeneous Catalyst: Role of the Solvent, Energy Fuels. 28 (2014) 4611-4621.

[29] M.V. Olarte, A.H. Zacher, A.B. Padmaperuma, S. D. Burton, H. M. Job, T. L. Lemmon, M. S. Swita, L. J. Rotness, G. N. Neuenschwander, J. G. Frye, D.C. Elliott, Stabilization of Softwood-Derived Pyrolysis Oils for Continuous Bio-oil Hydroprocessing, Top. Catal. 59 (2016) 55-64.

[30] D. C. Elliott, Biofuel from fast pyrolysis and catalytic hydrodeoxygenation, Curr. Opin. Chem. Eng. 9 (2015) 59-65.

[31] M. Ozagac, C. Bertino-Ghera, D. Uzio, M. Rivallan, D. Laurenti, C. Geantet, Understanding macromolecules formation from the catalytic hydroconversion of pyrolysis bio-oil model compounds, Biomass Bioenergy. 95 (2016) 182-193.

[32] M. Ozagac, C. Bertino-Ghera, D. Uzio, M. Rivallan, D. Laurenti, C. Geantet, Impact of guaiacol on the formation of undesired macromolecules during catalytic hydroconversion of bio-oil: A model compounds study, Biomass Bioenergy. 95 (2016) 194-205.

[33] J.T. Scanlon, D.E. Willis, Calculation of flame ionization detector relative response factors using the effective carbon number concept, J. Chromatogr. Sci. 23 (1985) 333-340.

[34] S. K. R. Patil, J. Heltzel, C. R. F. Lund, Comparison of Structural Features of Humins Formed Catalytically from Glucose, Fructose, and 5-Hydroxymethylfurfuraldehyde, Energy Fuels 26 (2012) 5281-5293.

[35] S. Li, S. Zhang, F. Feng, Y. Yan, Coke formation in the catalytic cracking of biooil model compounds, Environ. Progr. Sustain. Energy 34 (2015) 240-247. 
[36] V.N. Bui, D. Laurenti, P. Afanasiev, C. Geantet, Hydrodeoxygenation of guaiacol with CoMo catalysts. Part I: promoting effect of cobalt on HDO selectivity and activity, Appl. Catal. B Environ. 101 (2011) 239-245.

[37] V.N. Bui, D. Laurenti, P. Delichere, C. Geantet, Hydrodeoxygenation of guaiacol: Part II: support effect for CoMoS catalysts on HDO activity and selectivity, Appl. Catal. B Environ. 101 (2011) 246-255.

[38] F. Stankovikj, A.G. McDonald, G.L. Helms, M.V. Olarte, M. Garcia-Perez, Characterization of the water-soluble fraction of woody biomass pyrolysis oils, Energy Fuels. 31 (2017) 1650-166. 


\begin{tabular}{ccc}
\hline & $\begin{array}{c}\text { In this study } \\
\text { BO }\end{array}$ & $\begin{array}{c}\text { In the literature } \\
\text { bio-oils] }\end{array}$ \\
\hline Water (wt\%) & 26.4 & $20-35$ \\
\hline $\mathrm{C}(\mathrm{wt} \%)$ & 56.4 & $48-60$ \\
\hline $\mathrm{H}(\mathrm{wt} \%)$ & 6.4 & $5.9-7.2$ \\
\hline $\mathrm{O}(\mathrm{wt} \%)$ & 36.7 & $34-45$ \\
\hline $\mathrm{N}(\mathrm{wt} \%)$ & 0.0042 & $<0.3$ \\
\hline Viscosity (cSt) & $14.9\left(40^{\circ} \mathrm{C}\right)$ & $70-80\left(50^{\circ} \mathrm{C}\right)$ \\
\hline $\begin{array}{c}\text { Total Acid Number } \\
\text { (mgKOH.g }\end{array}$ & 91 & $0.02-1.2$ \\
\hline Ash (wt\%) & 0.2 & $1,100-1,300$ \\
\hline \begin{tabular}{c} 
Density at $20^{\circ} \mathrm{C}\left(\mathrm{kg} \cdot \mathrm{m}^{-3}\right)$ \\
\hline
\end{tabular} & 1,200 & 700
\end{tabular}

Table 1. Macroscopic analyses of the studied bio-oil (BO) compared to the average data for bio-oils in literature 